\title{
Experiential Learning Method and Hands-on Approach for Optimizing Learning on Signal and Systems Course
}

\author{
Nefy Puteri Novani ${ }^{1, *}$ Lathifah Arief ${ }^{2}$ \\ ${ }^{1.2}$ Department of Computer Engineering, Andalas University, Padang,Indonesia \\ "Corresponding author. Email: nefyputeri@it.unand.ac.id
}

\begin{abstract}
The development of learning methods carried out in this study is a hands-on approach applying experiential learning to students. The cycle begins with a student's learning experience, followed by an opportunity to reflect on that experience. Students can conceptualize and further what they experience and observe in their learning, which leads to future actions in which students' processes experiment with different behaviors. This research was conducted on 89 students of the Computer Engineering Department of Andalas University who attended the Signal and Systems course. The collection of student response data to the study was carried out by providing a survey in the form of a questionnaire. The analysis was carried out by using the concept proposed in the form of Kolb's Cycle of Experiential Learning which includes the experiential learning cycle. The application of experiential learning methods in Signal and Systems courses is considered effective to be applied to students in order to improve student skills through learning experiences obtained when hands-on. Students' perceptions of the hands-on method indicate that the method applied has been effective in providing basic understanding for students, improving skills and basic understanding of signals and systems.
\end{abstract}

Keywords: Experiential learning, Experience-based learning, Hands-on approach

\section{INTRODUCTION}

Contribution of the Signals and Systems course to the learning outcomes in the curriculum of the Computer Engineering department includes mastery to the field of computing, proficiency in using computational techniques and devices, the ability to think critically and obey scientific principles and have effective communication and long life learning with awareness to develop oneself lifelong in solving digital signal processing problems. The problem of digital signal processing is also related to the integration of data used in artificial intelligence, Big Data which is an inseparable part of the era of the Industrial Revolution

4.0. The concern is that Signals and Systems course can provide awareness to the students to apply the principles of longlife learning because the digital signal processing approaches are very useful as a preprocessing part on the data input for artificial intelligence applications and Big Data.

In the previous academic year, learning process of Signals and Systems courses has been implemented using the Cooperative Learning approach. In this method, the lecturer explains more about lectures such as lectures and after that gives examples of questions and discussions. Then students get learning experience in working on practice questions given by the lecturer. Students work on the practice questions in groups or in small groups, discussing to get solutions / answers to the practice questions given.

The evaluation toward this method showed that, this is not an effective way to make all students active in class activities. The supervision found that students with poor abilities sit together, so that students were less motivated to solve the given practice questions. When the lecturer asked these students the questions given, there was no discussion between them. In addition, due to the large number of students (> 30 students), lecturers did not have sufficient opportunities to encourage all students to always be active in every lecture meeting.

The development of learning methods carried out in this study is a hands-on approach applying experiential learning to students. The cycle begins with a student's learning experience, followed by an opportunity to reflect on that experience. Students can conceptualize and further what they experience and observe in their learning, which leads to future actions in which students' processes experiment with different behaviors. In this activity, the discussion of subject matter focuses on how 
students simulate or directly practice the theories learned in lectures using learning aids in the form of simulation software such as Matlab. The lecturer of the course provides material that will be practiced directly by students at each lecture meeting. The lecturer explains the general topic and the expected learning, acts as a motivator and facilitator in these activities and assesses each assignment / work resulting from student simulations.

To ensure a good level of understanding, this proposed learning method is also equipped with demonstration and classroom practice activities with a hands-on approach related to the theoretical material provided, and accompanied by designed assignments so that students can understand the application of the theories being taught properly. The application of the experiential learning method is expected to spur student motivation to study in groups and learn independently because students will do hands-on and simulate the theoretical principles of the signals and systems being taught.

The objectives of this study are to: 1) Improve and / or improve learning practices through new learning methods that can improve the quality of the process and student learning outcomes in the Signal and Systems course in the Department of Computer Systems Andalas University, and 2 ) Develop an assessment method students who are better able to assess all student activities in the learning process.'

\subsection{Related Work}

According to the generation type of assumptions, the existed work was divideede into two categories.

\subsubsection{Experiential Learning Theory}

Kolb's theory of Experiential Learning defines experiential learning as the process by which knowledge is created through the transformation of experiences. Kolb's Experiential Learning Theory presents four cycles of elements, including real experience, reflective observation, abstract conceptualization, and active experimentation [1]. The learners or students must go through each stage - experiencing, reflecting, thinking, and acting as shown in Figure 1. In the grasping experience the learner can perceive new information through experiencing the concrete, tangible, felt qualities of the world, relying on their senses and immersing themselves in concrete reality. Or the learner can experience the opposite, abstract conceptualization. This learning style preference would tend to perceive, grasp, or take hold of new information through symbolic representation thinking about, analyzing, or systematically planning. In the transforming experience the reflective observation ability tends to observe others who are involved in the experience and reflect on what happens while the active experimentation stage favors jumping in and starting doing things. It is important to note that the learner can enter the model at any stage (Kolb, 1984) [1].

Experiential learning approach has several components whose main profile is the concrete experience, reflective observation, active experimentation, and abstract conceptualization. The four stages of this learning experience will provide students with learning experiences including experiences to investigate, experience solving problems, and reflecting inward. [2]

\subsubsection{Experience-based Learning}

The application of direct experience-based learning methods allow students to find their own way of learning and learn from study guides other than lecturers. Students can actively interact with learning resources and reflect to gain the necessary learning experience. Learning skills are honed and learned over and over through a process of practice. In [3] get the results that students who feel more confident in their ability to write scientific papers after practicing through direct experience during lectures.

In [4] the hands on activity learning model is a learning model that is planned to help students develop higher-order thinking skills, in the sense that during the learning process students are actively involved and encourage the ability of students to understand the material presented or those who will think for themselves against what they have experienced in their daily lives, so that students' critical thinking skills can increase.

\subsection{Our Contribution}

This Research Activity for Development and Quality Assurance of Education is expected to be useful for increasing the success of the relevance of learning outcomes 1) For students, they can develop independence, cooperation, self-confidence in their own abilities in finding solutions to any problems encountered during the learning process. 2) For lecturers, research is a form of lecturer professionalism in their profession. This research can be used as a reference and become input for the next learning process that will be carried out. 3) For the Department of Computer Engineering in particular and Andalas University, the results of this study can be used as guidelines in making policies to improve the quality of learning. 


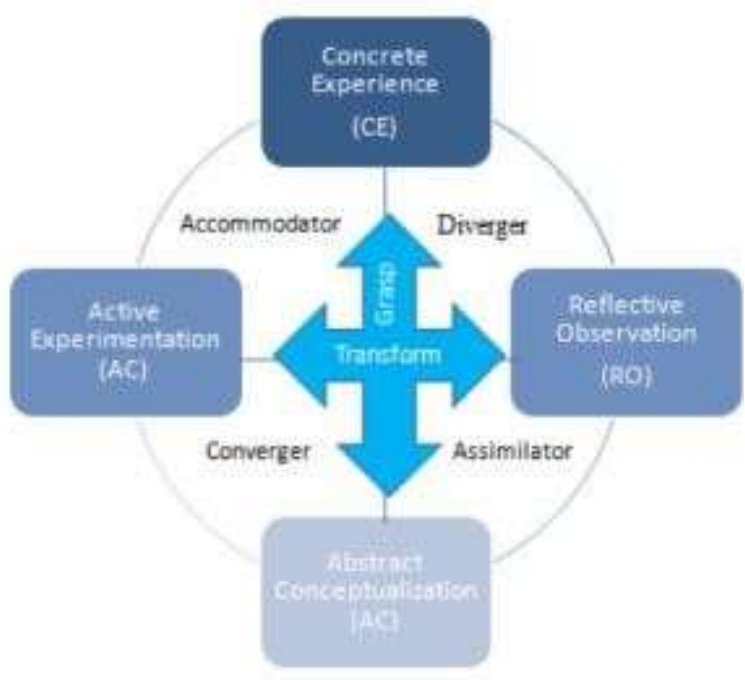

Figure 1 The Experiential Learning Cycle and Basic Learning styles (Kolb, 1984) [1]

\section{METHODS}

This research was conducted on 89 students of the Computer Engineering Department of Andalas University who attended the Signal and Systems course. The collection of student response data to the study was carried out by providing a survey in the form of a questionnaire. The analysis was carried out using the concept proposed in the form of Kolb's Cycle of Experiential Learning which includes the experiential learning cycle. The explanation of the method applied to the implementation of the experiential learning method is explained in a chronological way. The results of the analysis on the effectiveness of the method were identified after the final exam was carried out and presented descriptively.

\subsection{Study Design}

The subject of this study were students of the Andalas University Computer Engineering Department who participated in the Signal and Systems course in the even semester of 2019/2020. Students are divided into two classes. The distribution of students in each class is 46 students for class 01 , and 48 students for class 02 . This research was conducted in a half semester during the even semester of the 2019/2020 school year. The planning stage is carried out throughout weeks $6-8$, the implementation and observation stage is carried out at the 9-15 meeting and the evaluation stage is also carried out on weeks 15-16.

The learning method approach used is experiential learning with a hands-on approach to students. This research was conducted in four stages, namely define, design, develop, disseminate. [2].

Define Stage : front end analysis, learner analysis, concept analysis, task analysis, and specifying instruction objectives are carried out by analyzing the previous final score from students of Signal and Systems scores.

Design Phase : done by designing experiential learning tools including syllabus design, RPS, modules and assessment instruments.

Development Stage : The developmental testing stage is carried out by implementing learning in both classes through a hands-on approach. The purpose of this activity is to test the feasibility of experiential learning through a hands-on approach by students independently.

Disseminate Stage : This stage is carried out by implementing learning. Student ability is measured using test instruments to measure knowledge and attitudes, attitude scale questionnaires and student skill observation sheets in System Signal lectures with a hands-on approach.

Evaluation in this study is needed to assess the success of the learning and assessment methods developed in this research activity. The parameters used in the evaluation are:

a) The learning outcomes measured by instruments; independent assignments, exam questions at UAS. The exam questions will be designed based on the competency level planned at the RPS. Competencies that will be measured through exam questions are the level of cognitive and affective abilities.

b) The distribution of the final scores of this activity will be considered successful if the percentage of students who get grades below B is reduced from the previous year.

c) Student responses to the development of learning methods and/or assessments that are applied.

\subsection{Data Collection and Analysis}

The data collected in this study is the student test scores, grades assignments and student's perceptions of the application of learning methods experiential learning and hands-on and the motivation to learn the material independently. Measuring student response is done by distributing questionnaires to all students. The questionnaire used a Likert scale. Data were analyzed descriptively.

\subsection{Performance Indikator}

The indicators used to assess the effectiveness of the application of the method in this study are the learning outcomes and student responses. Learning outcomes are measured from student activity, assignments, and final exams. The criterion for success is the percentage of 
students who score A and a minimum of B compared to the academic score of the previous school year. Student response to the learning method applied is measured through a questionnaire. The criteria for success and effectiveness are if more than $70 \%$ of students respond positively to the learning methods applied.

\section{RESULTS AND DISCUSSION}

\subsection{Learning Outcomes at the end of Even Semester 2019/2020}

This study was conducted during the learning process after mid-test in the Signal and Systems course in the even semester of 2019/2020. The learning process takes place in 7 lecture meetings. Due to the conditions of the Covid-19 pandemic, the learning process has been transferred to learning from home. Experiential learning method with hands-on approach is applied using online learning media namely ilearn Andalas University. Fixed course material is delivered by considering the circumstances of the students as well as ease of access for students to carry out the process per college early.

In several online lecture meetings, schemes were made for students to remain active asking questions and discussing with their peers so that students could experience all the cycles of Kolb's Experiential Learning Theory elements, including:

1) Real Experience; with students observing the material provided by the lecturer.

2) Reflective Observation; Students observe, understand every material given and directly experiment following the steps using the Matlab / Octave / Octave Online Tools.

3) Abstract Conceptualization; form the concept of understanding independently and interact with each other in question and answer discussions with colleagues.

4) active experiment; doing practice assignments and homework assignments that are set by the teaching lecturer to support the achievement of learning objectives and outcomes.

By utilizing the Discussion Forum feature in ilearn, students can discuss each other with their peers and respond directly to the practice questions given by the lecturer during lectures. The method applied is quite effective considering the limitations in a pandemic situation and can eliminate student boredom in understanding the material presented by the lecturer.

Assessment in this course is carried out during the learning process, and assessment at the end of the learning process, namely through the Final Semester Examination and a large assignment. The results of the assessment show that the value distribution of Computer Engineering Study Program students in Signal and Systems courses by applying the experiential learning method with a hands-on approach is better than the distribution of student scores in the previous year. The distribution of students' final grades is presented in Figure 2.

Based on Figure 2. it is shown that the distribution of the final scores of students in the Signal and Systems course shows an increase by comparing the distribution of the final scores for Signal and Systems courses in the previous year. A- score was obtained by $8 \%$ of students, while in the previous year there were no students who received an A-. The lowest score obtained by students also changes. The increase in the distribution of students' final scores in the Signal and Systems course by applying a hands-on approach to the experiential learning method shows that this method is quite effective in the learning process.

\subsection{Students Response to the Development of Applied Learning Method}

Student response to the development of learning methods applied to the Signal and System course for the $2019 / 2020$ even semester is measured by an indicator of the impact of implementing experiential learning methods with hands-on in increasing student interest in learning and learning experience. The results showed that $71.32 \%$ of students stated that the method applied was effective. Students assess that the hands-on method applied in experiential learning is effective in improving soft skills and learning experiences obtained, consisting of the ability to communicate, work together and complete assignments or homework in groups. The experiential learning method applied to Signal and System course meetings is carried out, with the lecturer preparing the material for each lecture meeting in the form of tutorials that must be hands-on by students either independently or in groups.

Then the lecturer prepares an online discussion room on ilearn so that students can send questions to the online discussion room if they want to ask. This learning process was repeated several times in 7 lecture meetings after the UTS.

\section{CONCLUSION}

The application of experiential learning methods in Signal and Systems courses is considered effective to be applied to the students in order to improve student skills 


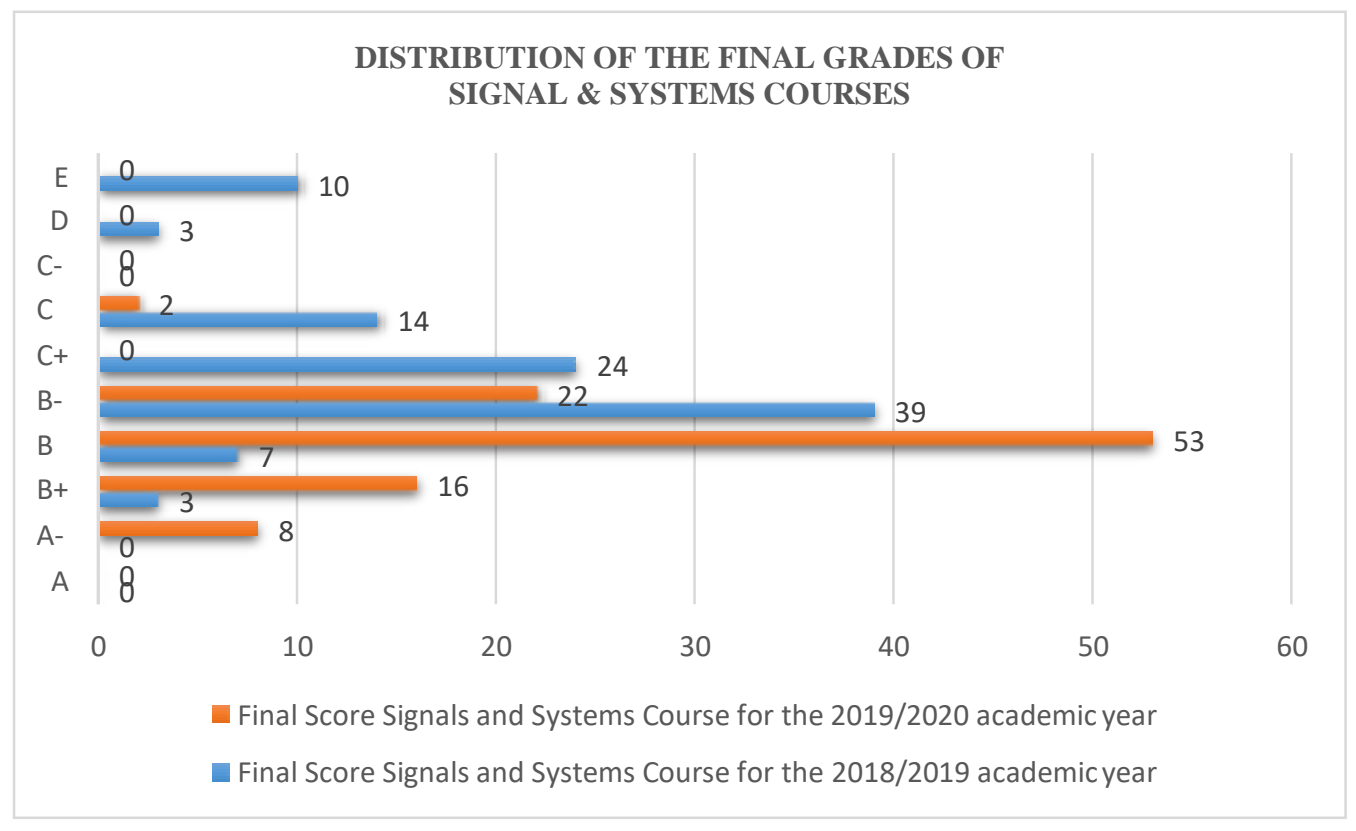

\section{Figure 2 Comparison of the Distribution of the Final Score of Signal and System Courses}

through learning experiences obtained when hands- on. Students' perceptions of the hands-on method indicate that the method applied has been effective in providing basic understanding for students, improving skills and basic understanding of signals and systems as a condition for continuing to study Digital Signal Processing in the following semester.

\section{ACKNOWLEDGMENTS}

This work was supported by the institution of Educational Development and Quality Assurance, thanks for funding Research Development and Quality Assurance of Educations for Signal and System course. The students of Computer Engineering Department of Andalas University who joined the Signal and Systems class, thank you for the participation and responds.

\section{REFERENCES}

[1] McCarthy, M. (2010). Experiential Learning Theory: From Theory to Practice. Journal of Business \& Economics Research (JBER), 8(5).
[2] Istikomayanti, Y., Suwono, H., \& Irawati, M.H. (2016). Experiential learning group investigations as effort to develop environmental literacy ability at 5th Grade Students of Madrasah Ibtidaiyah. JPBI (Jurnal Pendidikan Biologi Indonesia), 2(1), pp. 57-71.

[3] Yanto, Hery., The, Latifah.(2018). Students Academic Writing Skills and Self Efficacy Through Experiential Learning. Metalingua, 16(2), pp. 201-210.

[4] Erti, M. P.(2017). Application of the hands on activity model to improve students' critical thinking skills in physics learning MTSN IV Koto Aur Malintang. Natural Science: jurnal Penelitian Bidang IPA dan Pendidikan IPA, 3(1), pp. 383390.

[5] Meitikasari, A. (2016). Experiential Learning (El): an effective teaching method to construct students' writing skill viewed from self-efficacy. ICTTE, 1(1), pp. 1015-1022

[6] Zahara, L. (2018). Application of hands on activity model to improve student learning outcome. Kappa Journal, 2(2), 28-33. 